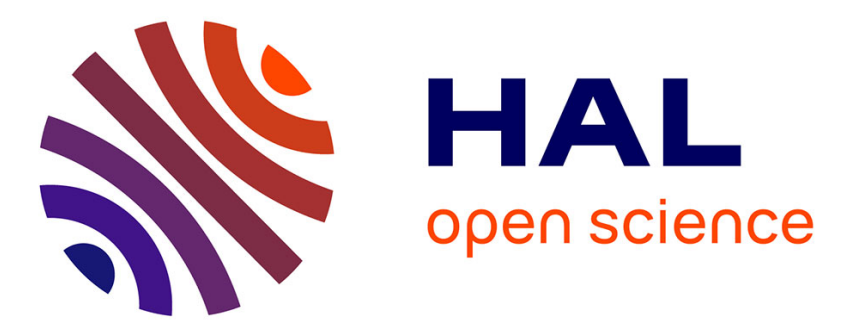

\title{
Discharge rate of explosive volcanic eruption controls runout distance of pyroclastic density currents
}

\author{
Olivier Roche, Nourddine Azzaoui, Arnaud Guillin
}

\section{To cite this version:}

Olivier Roche, Nourddine Azzaoui, Arnaud Guillin. Discharge rate of explosive volcanic eruption controls runout distance of pyroclastic density currents. Earth and Planetary Science Letters, 2021, 568, pp.117017. 10.1016/j.epsl.2021.117017 . hal-03254073

\section{HAL Id: hal-03254073 \\ https://hal.uca.fr/hal-03254073}

Submitted on 16 Jun 2021

HAL is a multi-disciplinary open access archive for the deposit and dissemination of scientific research documents, whether they are published or not. The documents may come from teaching and research institutions in France or abroad, or from public or private research centers.
L'archive ouverte pluridisciplinaire HAL, est destinée au dépôt et à la diffusion de documents scientifiques de niveau recherche, publiés ou non, émanant des établissements d'enseignement et de recherche français ou étrangers, des laboratoires publics ou privés.

\section{(1) (1) $\$$}

Distributed under a Creative Commons Attribution - NonCommercial - NoDerivatives 44.0 


\title{
Discharge rate of explosive volcanic eruption controls runout distance of pyroclastic density currents
}

\author{
Olivier Roche $^{1 *}$, Nourddine Azzaoui ${ }^{2}$, Arnaud Guillin ${ }^{2}$ \\ ${ }^{1}$ Laboratoire Magmas et Volcans, University Clermont Auvergne, CNRS, IRD, OPGC, 63000 \\ Clermont-Ferrand, France \\ ${ }^{2}$ Laboratoire de Mathématiques Blaise Pascal, University Clermont Auvergne, CNRS, 63000 Clermont- \\ Ferrand, France \\ * Corresponding author (olivier.roche@uca.fr)
}

\begin{abstract}
We address, through quantitative analysis of results from independent studies, the control of the discharge rate of explosive volcanic eruptions on the runout distance of highly hazardous pyroclastic density currents. We analyze with statistical methods data from 47 well-documented currents with runouts of $\sim 3-185 \mathrm{~km}$ and generated by minor eruptions to super-eruptions with discharge rates $\mathrm{Q} \sim 10^{7}$ $10^{12} \mathrm{~kg} / \mathrm{s}$. Our analysis shows first that the discharge rate during the phase of pyroclastic density currents is on average 13.6 times greater than the rate during the preceding plinian phase. We further find that the runout of both dilute turbulent currents and of two-layer flows with a concentrated base correlates remarkably well with the discharge rate. By applying the power law relationships we infer, we next model the as yet unknown discharge rates of over 53 events, including 27 super-eruptions. At a given rate, dilute currents travel on land generally farther than their concentrated counterparts, and they are even more mobile when propagating over water. We further demonstrate that the runout of dilute current scales with $(\mathrm{Q} / \mathrm{w})^{0.5}$, with $\mathrm{w}$ the particle settling velocity, in agreement with theory. Assuming concentrated PDCs obey the same principle we infer particle settling velocities of $\sim 1-10 \mathrm{~m} / \mathrm{s}$ for these currents. We show also that the classical deposit aspect ratio, AR, allows to discriminate between emplacement from dilute $\left(\mathrm{AR}<\sim 5 \times 10^{-5}\right)$ and concentrated $\left(\mathrm{AR}>\sim 5 \times 10^{-5}\right)$ current, which permits us to discuss the dynamics of PDCs produced by the Ito (29 ka) and Taupo (AD 232) eruptions.
\end{abstract}

Keywords: explosive volcanism, discharge rate, pyroclastic density current, runout distance, power law relationship, super-eruption.

\section{Introduction}

Explosive volcanic eruptions generate jets of gas and entrained solid particles that rise into the atmosphere, where they ingest and heat ambient air to form buoyant plinian plumes. Variations in source parameters, however, may cause the jets to turn totally or partially into collapsing fountains (see Valentine, 2020, for recent advances), which generate devastating pyroclastic density currents (PDCs) that propagate over considerable distances and disseminate large amounts of ash into the atmosphere. The discharge rate is fundamental in controlling the dynamics of explosive volcanic events. Many studies have shown that the plume height increases with the mass discharge rate (MDR) (see the review of Mastin et al., 2009, and references therein), which is up to $\sim 10^{9} \mathrm{~kg} / \mathrm{s}$ for single-vent eruptions. Larger MDRs of $\sim 10^{9}-10^{11} \mathrm{~kg} / \mathrm{s}$ characterize eruptions from multiple vents during caldera collapse or from elongated vents fed by regional dykes (Mason et al., 2004; Costa et al., 2011; Newhall et al., 2018), and under these circumstances super-eruptions expelling more than $\sim 450 \mathrm{~km}^{3}$ of magma have long-term severe consequences on the whole Earth scale (Self, 2006; Costa et al., 2014).

The increase in PDC runout distance with MDR, coupled with that in plume height, is a longstanding issue (Cas and Wright, 1987, p. 249; Bursik and Woods, 1996; Dufek and Bergantz, 2007; Esposti Ongaro et al., 2008; Shimizu et al., 2019). However, a quantitative relationship between runout 
and MDR remains elusive owing to the limited number of cases investigated, and it is yet to be determined from a statistically significant number of data of different eruptions. This issue is fundamental in the context of hazard assessment since runout determines the area impacted by destructive currents. In order to investigate the control of MDR on PDC runout, we present a comprehensive set of data for 40 well-documented eruptions of Volcanic Explosivity Index or Magnitude $\sim 1-8$, with bulk volumes of $\sim 10^{-4}-10^{3} \mathrm{~km}^{3}$, MDR of $\sim 10^{7}-10^{12} \mathrm{~kg} / \mathrm{s}$, and which generated 47 PDCs with runout distances of $\sim 3-185 \mathrm{~km}$. We use statistical methods to treat the data, which permit us to determine power law relationships that we use to infer MDR from runout distances of PDCs for another set of 53 eruptions, including 27 super-eruptions.

\section{Methodology}

\subsection{The dataset}

We searched for data on PDCs in $~ 120$ original references, and in some cases we found complementary information in the LaMEVE database (Crosweller et al., 2012). Note that all data regarding PDC runout distances and deposit grain sizes, in particular, have been extracted from the original publications. When volume discharge rates are given in references we convert them into MDR by considering a typical magma density $\rho=2500 \mathrm{~kg} \mathrm{~m}^{-3}$. Supplementary Table 1 presents the data of PDCs on land and/or over water, including in particular mass discharge rates and runout distances. For convenience we use simplified names (e.g., Ito) to designate given eruptions. We consider both dilute and concentrated PDCs, depending on the inferred dominant mass transport mechanism (Breard et al. 2018), as broadly acknowledged by the volcanological community (Fig. 1). Although this dichotomy may seem simplistic with respect to the complexity of natural phenomena, the consistency of the results we present below suggests that it is not unfounded.

Dilute PDCs (Fig. 1a) are turbulent mixtures with typical solid bulk concentration $<1 \mathrm{vol} . \%$ and with possible density stratification. The particles that cannot be carried by the gas flow settle to the current base to form a bedload of higher concentration, which arises as a consequence of interaction of the turbulent flow with the substrate and from which deposition occurs (Valentine, 1987; Fauria et al., 2016; Dellino et al., 2019). Entrainment and heating of ambient air by the turbulent flow decrease the density of the current, which lifts off when it becomes buoyant, hence setting the runout distance (Andrews and Manga, 2012). Note that we do not consider the case of blast-PDCs, which may have higher particle bulk concentrations because of their high momentum density (Esposti-Ongaro et al., 2011). Concentrated PDCs (Fig. 1b) consist of a dense flow transporting most of the solid mass and coupled to an upper turbulent dilute suspension, hence forming a two-layer current in which two fundamentally different physics operate (Brown and Branney, 2013; Breard et al., 2016; Shimizu et al., 2019). The dynamics of the concentrated basal flow are controlled by momentum exchange between the particles and possibly by gas pore pressure (Roche et al., 2016; Lube et al., 2019). In the context of pyroclastic fountain collapse, the concentrated flow forms at the impact zone because of weak gasparticle coupling (Valentine, 2020), or further away if it is fed at a high particle settling rate by the dilute suspension (Branney and Kokelaar, 2002). The runout distance is controlled by energy dissipation caused essentially by particle-particle interactions and, in case the two layers are coupled, by the ratio of the speed of deposition from the concentrated flow to the speed at which particles settle from the suspension (Shimizu et al., 2019). Therefore, in some cases the dilute suspension may form deposits that extend beyond those of the concentrated flow though they have volumes that in proportion are significantly smaller. A few examples of this configuration are denoted dilute in Supplementary Table 1.

We classified the currents according to authors' conclusions based essentially on architecture and sedimentological characteristics of the deposits, with one exception (Taupo, AD 232). We paid particular attention to eruptions that produced currents of both types and/or in various environments in order to attribute the correct eruptive parameters to the corresponding stratigraphic units described in references. In some cases the authors clearly identify deposits generated by successive dilute or concentrated PDCs (El Chichon, Ksudach, Llopango, and Okmok, to mention examples given in Supplementary Table 1) or by the concentrated and dilute parts of two-layer currents (Ksudach, Okmok, 
and possibly Campanian). Some eruptions produced currents both on land and over water (Campanian, Kos, Okmok, and Tosu).
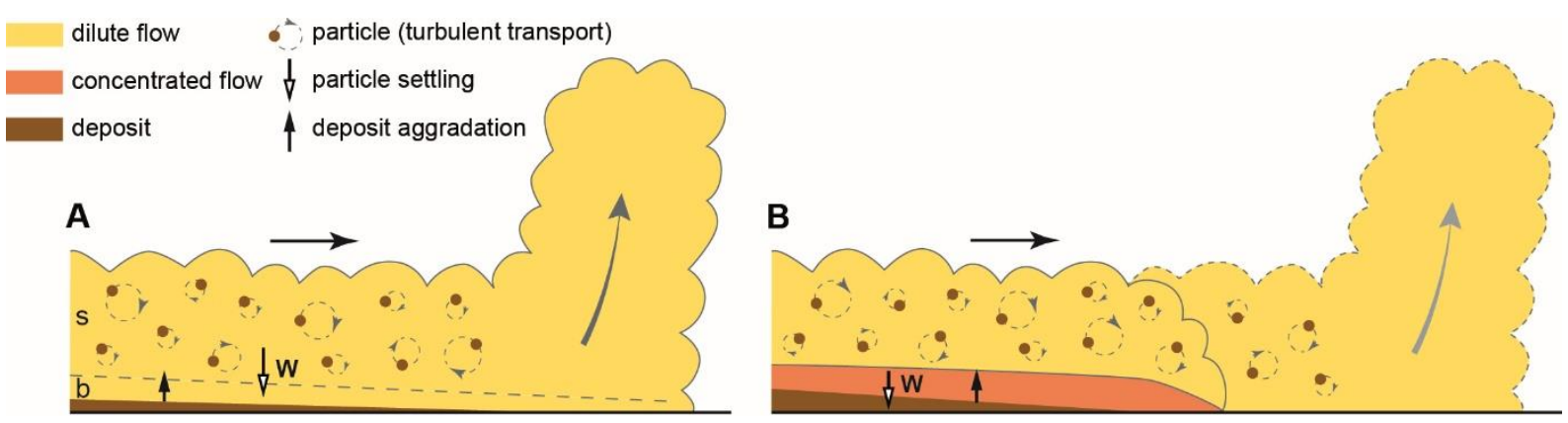

Fig. 1. Types of pyroclastic density currents. Horizontal arrows indicate flow direction. (A) Dilute turbulent PDC with a suspended load (s) and a bedload (b). (B) Concentrated PDC overridden by a dilute suspension (two-layer model); the two layers may exchange particles through a sharp or transitional interface, and PDC runout is controlled by deposition from the concentrated flow but in some cases the suspension may travel further (dashed line). The deposit aggrades as a consequence of particle settling (at speed w) within the dilute (A) or the concentrated (B) PDCs. Dilute suspension lift-off is shown by large gray arrows.

\subsection{Mass discharge rate}

The values of discharge rates published in literature are obtained in three ways. Most rates are given for the plinian phase and are derived from the height of the plume determined from isopleths of the fall deposits (these data are noted $\mathrm{Q}_{\mathrm{h}}$ in Supplementary Table 1). Discharge rates are also given for the PDC phase, either from models of PDCs or of the so-called co-ignimbrite plumes $\left(\mathrm{Q}_{\mathrm{m}}\right)$, or from the ratio of the volume of the deposits over the duration of the flows, then converted to MDR $\left(\mathrm{Q}_{\mathrm{v}}\right)$. It is well known that the transition from plinian to a PDC phase is often favored by an increase in MDR (Wilson, 1980; Carey et al., 1990; Bursik and Woods, 1996; Carazzo et al., 2008; Costa et al., 2018), possibly related to conduit enlargement caused by erosion (Koyaguchi et al., 2010) and/or onset of caldera collapse with opening of multiple vents or ring-fractures, though decrease in volatile content may also contribute (Carazzo et al., 2008).

We consider nine well-documented eruptions with MDRs estimated in different ways (Fig. 2). In order to quantify the difference between MDR estimates for the plinian phase $\left(\mathrm{Q}_{\mathrm{h}}\right)$ and those of the PDC phase $\left(\mathrm{Q}_{\mathrm{m}}\right)$ we sort the data by increasing value of $\mathrm{Q}_{\mathrm{h}}$ and report the corresponding values of $\mathrm{Q}_{\mathrm{m}}$ (Fig. 2). Then we calculate the best-fit lines $\log \mathrm{Q}_{\mathrm{h}}=\mathrm{a}_{\mathrm{h}} x+\mathrm{b}_{\mathrm{h}}$ and $\log \mathrm{Q}_{\mathrm{m}}=\mathrm{a}_{\mathrm{m}} x+\mathrm{b}_{\mathrm{m}}$ (full lines in Fig. 2), with $\mathrm{a}_{\mathrm{h}, \mathrm{m}}$ and $\mathrm{b}_{\mathrm{h}, \mathrm{m}}$ the respective slopes and origins and $x$ the ranking. We impose the slope $\mathrm{a}_{\mathrm{m}}=0.24$ to fit the data of $\mathrm{Q}_{\mathrm{h}}$ so that $\log \mathrm{Q}_{\mathrm{h}}=\mathrm{a}_{\mathrm{m}} x+\mathrm{b}_{\mathrm{h}}$, with $\mathrm{b}_{\mathrm{h}}$, the origin of this trend (red dashed line in Fig. 2). We find the origin $b_{\mathrm{h}}$, from the minimum of the function

$$
\phi\left(b_{h^{\prime}}\right)=\sum_{i=1}^{n}\left[\log Q_{m, i}-\left(a_{m} x_{i}+b_{h^{\prime}}\right)\right]^{2}
$$

that is, when the derivative of the function $\phi$ is equal to zero, so that

$$
b_{h^{\prime}}=\frac{1}{n} \sum_{i=1}^{n}\left(\log Q_{m, i}-a_{m} x_{i}\right)
$$

Fig. 2 shows that $b_{h}=7.62$, so that the ratio $Q_{m} / Q_{h}=10^{\text {bm/bh' }}=13.71$ (with $b_{m}=8.66$ ). We repeat the procedure described above by considering the slope $\mathrm{a}_{\mathrm{h}}=0.19$ to fit the data of $\mathrm{Q}_{\mathrm{m}}$ and we obtain a similar ratio $\mathrm{Q}_{\mathrm{m}} / \mathrm{Q}_{\mathrm{h}}=10^{\mathrm{bm} / \mathrm{bh}}=13.47$. This gives us a mean ratio $\mathrm{Q}_{\mathrm{m}} / \mathrm{Q}_{\mathrm{h}}=13.59$. Similarly, we find a very close value of 13.63 if the data of $\mathrm{Q}_{\mathrm{m}}$, instead of $\mathrm{Q}_{\mathrm{h}}$, are sorted by increasing values. In summary, we find that for a given eruption the discharge rate during the PDC phase is on average 13.6 times greater than that during the preceding plinian phase. The advantage of our method is that it does not give too much weight to the highest estimates since the values of MDRs vary over three orders of magnitude (note that an analysis considering mean values would give a ratio of about 20 , which would have a negligible influence on our results). Therefore, in our analysis we consider corrected values $\mathrm{Q}_{\mathrm{hc}}=13.6 \times \mathrm{Q}_{\mathrm{h}}$ to characterize the discharge rates of the PDC phase, to calculate mean rates from the different estimates, and to quantify the relationship between MDR and PDC runout (see Fig. 1 in Supplementary Material 
for comparison of $\mathrm{Q}_{\mathrm{hc}}$ with other MDR estimates). Supplementary Table 1 gives the values of $\mathrm{Q}_{\mathrm{v}}, \mathrm{Q}_{\mathrm{h}}$ and $\mathrm{Q}_{\mathrm{m}}$ available in literature as well as our corrected values $\mathrm{Q}_{\mathrm{hc}}$. We calculate mean MDR values for the PDC phase, $\mathrm{Q}$, from $\mathrm{Q}_{\mathrm{hc}}$ and $\mathrm{Q}_{\mathrm{m}}$. We do not consider $\mathrm{Q}_{\mathrm{v}}$, which is often poorly constrained, unless it is the only datum available (Krakatau and Peach Spring).

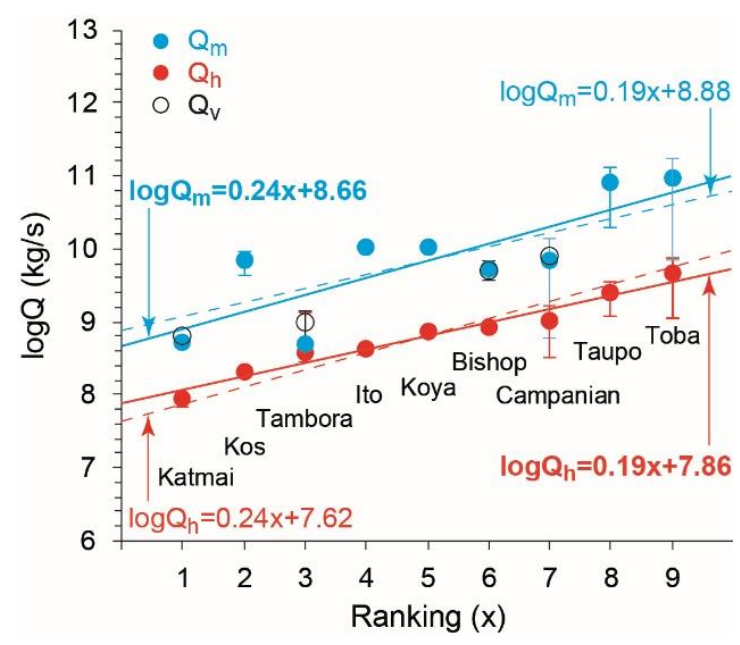

Fig. 2. Mass discharge rates $\mathrm{Q}_{h}$ (plinian phase) and $\mathrm{Q}_{\mathrm{m}}$ (PDC phase) of nine well-documented eruptions. The data are sorted by increasing value of $\mathrm{Q}_{\mathrm{h}}$ and best-fit lines through the data are shown (solid lines). Dashed lines illustrate our calculation that on average $\mathrm{Q}_{\mathrm{m}}$ is 13.6 times greater than $\mathrm{Q}_{\mathrm{h}}$ (see text for detail). Values of discharge rates $\mathrm{Q}_{\mathrm{v}}$ (PDC phase) available for four eruptions are very close to those of $\mathrm{Q}_{\mathrm{m}}$. Error bars indicate the minimum and maximum estimates.

\subsection{Runout of pyroclastic density currents}

Another fundamental issue for our study is the determination of the PDC runout, which is not trivial. For most of the cases presented in Supplementary Table 1 we determine ranges and mean values for runouts from maps given in publications. As shown in Fig. 3, we calculate a mean runout distance from measurements in several sub-perpendicular directions if deposits are distributed radially from the source (most cases given in Supplementary Table 1), and in cases of caldera-forming eruptions runout is measured from the topographic rim. Otherwise, we accept the runout distance stated by the authors if maps are not available.

It should be noted that there are several limitations to estimating the runout distances of PDCs from the spatial distribution of their deposits: (1) Runouts, as well as volumes, are commonly minimum estimates because of erosion since PDC emplacement and as some PDC may have entered into the sea (e.g. Toba; Chesner and Rose, 1991). (2) The dilute component of some two-layer PDCs may travel farther than the concentrated basal flow (Fig. 1), but the respective deposits of the two parts are generally well identified (Burgisser, 2005; Cook et al., 2016). (3) For given eruptive parameters, a significant slope angle and/or flow confinement in valleys generally cause longer runouts compared to those over flat and unconfined surfaces, although steep slopes may decrease the runout of dilute PDCs due to enhanced air entrainment (Esposti-Ongaro et al., 2002). (4) For large-volume PDCs spreading radially as in case of caldera-forming eruptions, (i) the locations of the vents are sometimes poorly constrained, (ii) topographic barriers reduce runout in some directions while channelization increases it in others (Henry and Faulds, 2010), and (iii) runout must be corrected in case of regional tectonic extension since deposition (Best et al., 2013; Roche et al., 2016). 


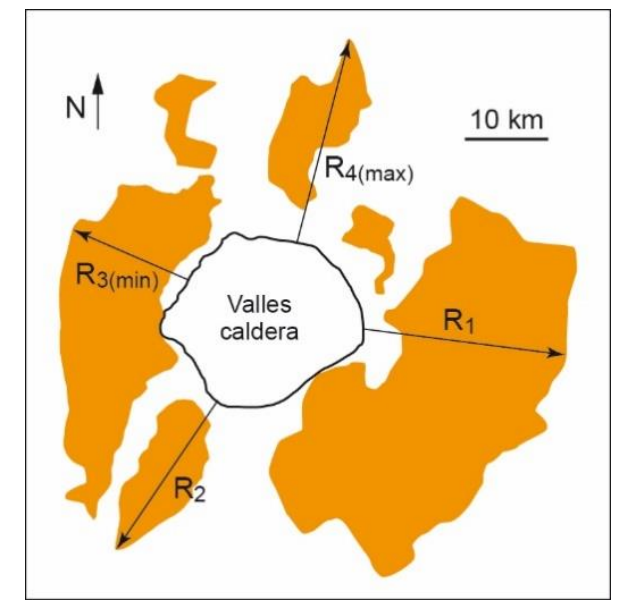

Fig. 3. Method used for estimating the runout of PDC from maps of deposits distributed radially. Runout is measured in sub-perpendicular directions to calculate a mean value and a range given by the minimum $\left(R_{\min }\right)$ and maximum $\left(\mathrm{R}_{\max }\right)$ estimates. Example of the lower Bandelier Tuff (Valles Caldera, New Mexico; from Cook et al., 2016).

\section{Results and analysis}

\subsection{Runout of pyroclastic density currents as a function of mass discharge rate}

Fig. 4 shows that the runout of PDCs on land correlates remarkably well with the mean MDR, with runout of dilute currents generally longer than that of concentrated ones at a given MDR. The bestfit lines obtained via regression are

$$
R_{c}=55 \times 10^{-4} Q^{0.373}
$$

for concentrated PDCs, with coefficient of determination $\mathrm{R}^{2}=0.945$, and

$$
R_{d}=11 \times 10^{-4} Q^{0.468}
$$

for dilute PDCs, with $\mathrm{R}^{2}=0.910$. The data for dilute PDCs over water are too sparse to define a clear trend but nevertheless show generally longer runouts than those on land, for a given MDR.
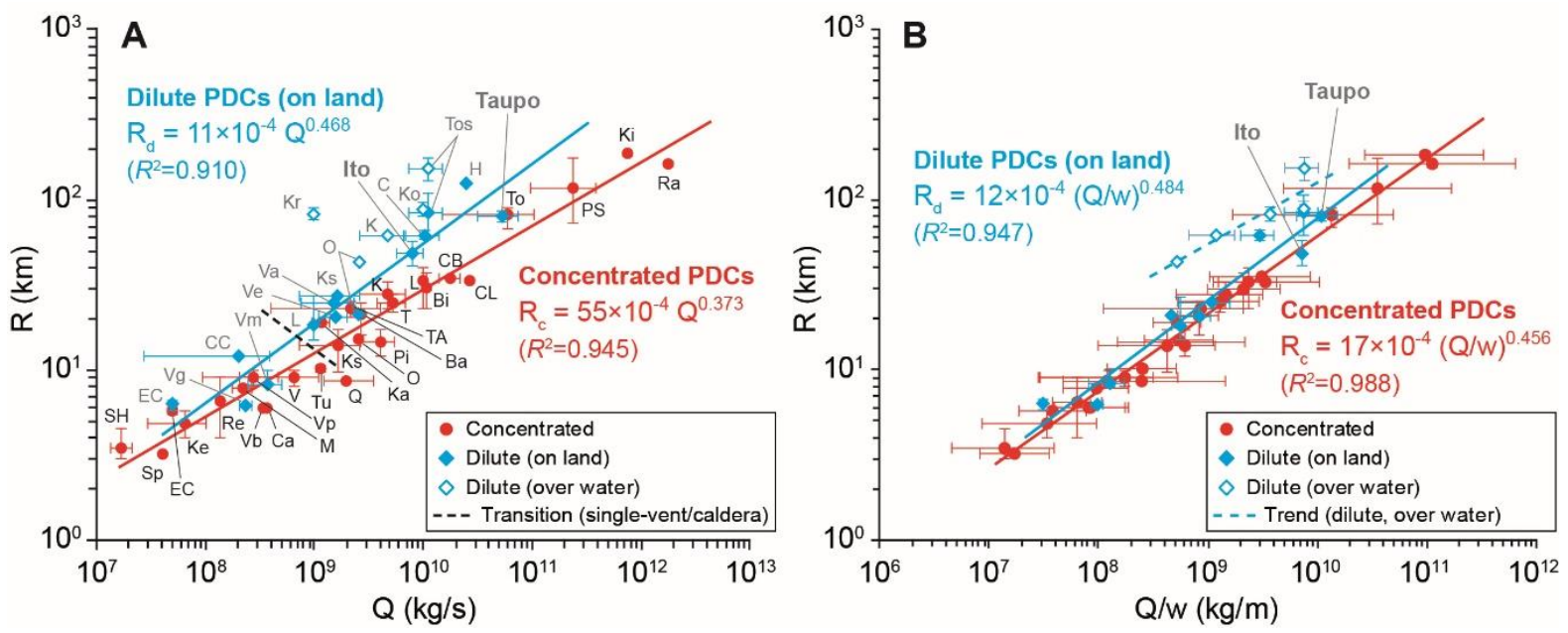

Fig. 4. Power law relationships for PDC runout distance as a function of mass discharge rate. Detailed data are given in Supplementary Table 1. The specific cases of Ito and Taupo are discussed in the main text. (A) Runout $\mathrm{R}$ as function of mean mass discharge rate $\mathrm{Q}$, with best-fit lines for dilute $\left(\mathrm{R}_{\mathrm{d}}\right)$ and concentrated $\left(\mathrm{R}_{\mathrm{c}}\right)$ PDCs on land. The black dashed line delimits the fields of single-vent (lower estimates) and caldera-forming (higher estimates) eruptions. Dilute PDC on land and/or over water (bold grey letters): C (Campanian), CC (Cordon Caule), EC (El Chichon, B-S2), H (H ash flow), Ito, K (Kos, unit E), Ko (Koya), Kr (Krakatau), Ks (Ksudach), L (Llopango, unit E), O (Okmok), Ve (Vesuvius AD79), Va (Vesuvius, Pomici di Avellino), Vg (Vesuvius, Greenish pumice), Vm 
(Vesuvius, Pomici di Mercato), Taupo, Tos (Tosu). Concentrated PDC (black letters): Ba (Bandelier Tuff), Bi (Bishop Tuff), Ca (Calbuco), CB (Cerro Blanco), CL (Crater Lake), EC (El Chichon, B-F2), Ka (Katmai), Ke (Kelud), Ki (Kidnappers), K (Kos), Ks (Ksudach), L (Llopango, unit F), M (Mount St-Helens), O (Okmok), PS (Peach Spring), Pi (Pinatubo), Q (Quizapu), Ra (Rattlesnake), Re (Reventador), SH (Soufrière Hills), Sp (Spurr), T (Tambora), Tu (Tungurahua), TA (Tuscalano Artemisio), To (Toba), Vb (Vesuvius, Pomici di base), Vp (Vesuvius, Pollena), V (Vesuvius AD 1631). (B) Runout R as function of the ratio of Q over the particle settling velocity w, with best-fit lines for dilute $\left(\mathrm{R}_{\mathrm{d}}\right)$ and concentrated $\left(\mathrm{R}_{\mathrm{c}}\right)$ PDCs on land. For concentrated PDCs, values of $\mathrm{w}$ are estimated from a regression optimization procedure (see section 3.2.2) and error bars take into account variations of both $\mathrm{Q}$ and $\mathrm{w}$. The dashed line indicates the trend for dilute PDCs over water.

We justify statistically the distinction between concentrated and dilute PDCs by model selection and a Monte Carlo procedure considering uncertainties for both $\mathrm{R}$ and $\mathrm{Q}$, as discussed below, and by Monte Carlo leave-one-out semi-supervised procedure (Supplementary Material). At first, we use model selection to infer whether the link between runout, $\mathrm{R}$ and mass discharge rate, $\mathrm{Q}$, is defined by one or two distinct power law relationships depending on the nature (i.e., concentrated or dilute) of the PDC. Model selection is done by penalized regression methods (Hastie et al., 2009), including Akaike information criterion (AIC) or Bayesian information criterion (BIC), which is denoted generically Penal in Eq. (5) below. The purpose is to penalize models with a high number of parameters and favour parsimonious ones. Specifically, we optimize the number of parameters and the quality of the models by analysing

$$
\| \log (R)-\mu(\text { Type })-\alpha(\text { Type }) \log (Q) \|^{2}+\text { Penal. }
$$

Statistical analysis indicates that the data are defined by two distinct power laws (see further details in Supplementary Material). As there are uncertainties in both $\mathrm{R}$ and $\mathrm{Q}$ for most of the eruptions, we have also used an original Monte Carlo procedure that simulates uniform laws for the range of these two parameters. This permits us to provide consolidated versions of the regression parameters as well as confidence and prediction intervals (Fig. 5). Moreover, as the type of the current may have been missspecified we also provide a leave-one-out strategy to qualify the type of the left-out current to obtain the closest prediction by linear regression, logistic regression or random forests (Supplementary Table 1 and Supplementary Material). In detail, each PDC was left-out successively and for each case we did 10000 Monte-Carlo simulations to calibrate the classification procedure and to determine to which tendency (concentrated or dilute) the left-out PDC was the closest. This method permitted us to identify a few cases whose type was against the classification based on conclusions of authors (Supplementary Table 1).
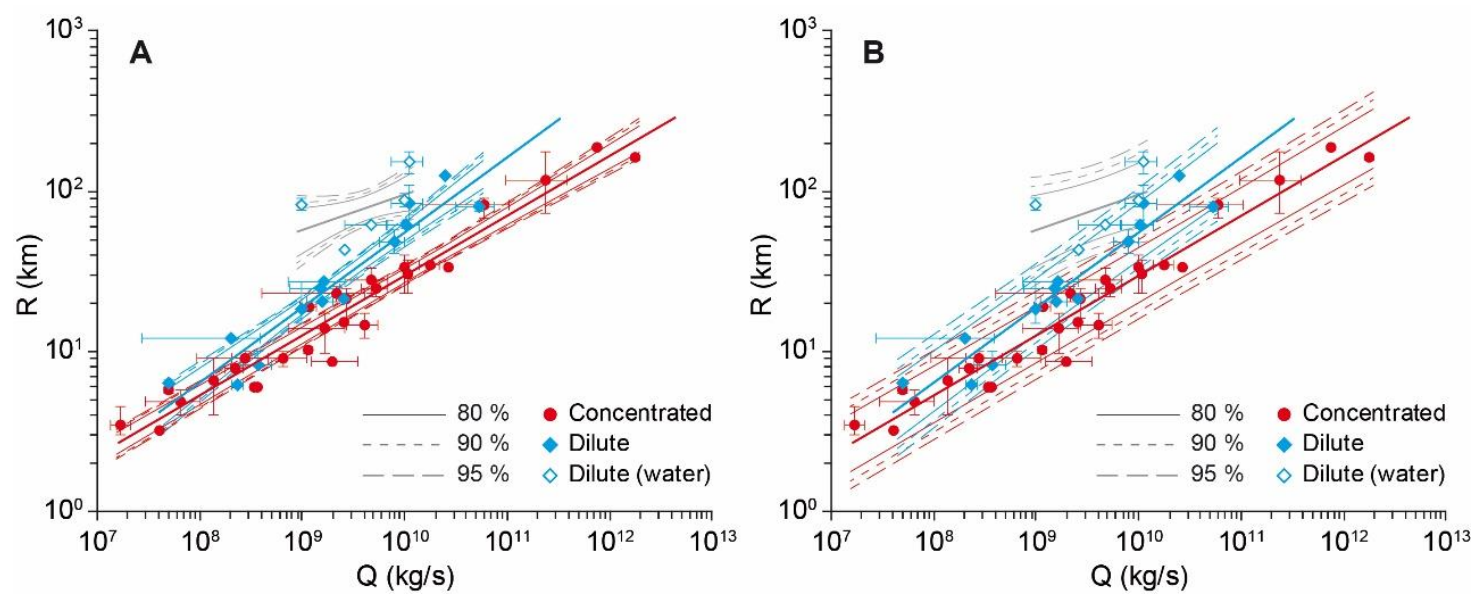

Fig. 5. PDC runout, R, as function of mean mass discharge rate, $\mathrm{Q}$, with (A) confidence intervals and (B) prediction intervals with probabilities of 80,90 and $95 \%$ for dilute or concentrated PDCs. Lower and upper estimates of the fitting parameters for each confidence intervals are given in Supplementary Table 3 (see Supplementary Material). 


\subsection{Effect of particle settling}

\subsubsection{Dilute currents}

Theoretical considerations on the physics of turbulent currents allow further analysis of the data for dilute PDCs. The runout of axisymmetric currents scales with $\left(Q^{\prime} / w\right)^{0.5}$, which has the dimension of length, with Q' the volume flux and $\mathrm{w}$ the particle settling velocity (Dade and Huppert, 1995). This scaling indicates that the flow dynamics depends on the balance between advection and settling rates for the solid particles, the latter varying with the particle size and decreasing progressively the PDCs mass, while the exponent 0.5 expresses the radial spreading of the current (it is equal to 1.0 if the flow is unidirectional). In the context of our study, the runout should scale equally with $(\mathrm{Q} / \mathrm{w})^{0.5}$ since we assume a constant magma density $\rho=Q / Q^{\prime}=2500 \mathrm{~kg} \mathrm{~m}^{-3}$ to convert discharge rates. Therefore, we consider the particle sizes of deposits from dilute PDCs given in references and we calculate the corresponding settling velocities (Supplementary Table 1). The mean particle size $\mathrm{Md}_{\phi}$ increases with $\mathrm{R}_{\mathrm{d}} / \mathrm{Q}^{0.468}$ (with $\mathrm{R}_{\mathrm{d}}$ the runout distance) defined according to Eq. 4 (Fig. 6), showing that at a given MDR the runout distance increases as particle size (and hence the settling velocity) decreases, in agreement with the physics (cf. Dellino et al. 2019). Fig. 4b shows that the best-fit line through the data for deposits of dilute PDCs on land gives

$$
R_{d}=12 \times 10^{-4}(Q / w)^{0.484}
$$

with $\mathrm{R}^{2}=0.947$. Compared to Eq. 4 , the effect of $\mathrm{w}$ is to collapse the data onto the best-fit line, and the exponent is closer to the theoretical value of 0.5 . Notice that $R_{d}$ scales with $(\mathrm{Q} / \mathrm{w})^{0.353}$ if $\mathrm{Q}$ is calculated from uncorrected values $\mathrm{Q}_{\mathrm{h}}$ (Fig. 2 in Supplementary Material), which proves that the corrections we make are relevant. The fact that the natural data are in agreement with the theoretical prediction supports the idea that the runout depends on the mean particle size, as considered for instance by Dade and Huppert (1996). However, other works have shown that the runout is controlled by the finest particles (e.g. Bonnecaze et al., 1996) and care must be taken when interpreting the data in Fig. 4b.

In Fig. 4b, we highlight the specific case of Taupo (with relatively coarse $\mathrm{Md}_{\phi}=0$ and high $\mathrm{w} \sim 5$ $\mathrm{m} / \mathrm{s}$ ), whose data nearly coincide with the best-fit line while they are closer to the trend of concentrated PDC if $R_{d}$ is plotted against $\mathrm{Q}$ as in Fig. 4a. Additionally, Q/w ratios allow identification of a fairly welldefined trend for dilute PDC over water, with runouts about twice as long as on land at given MDR.
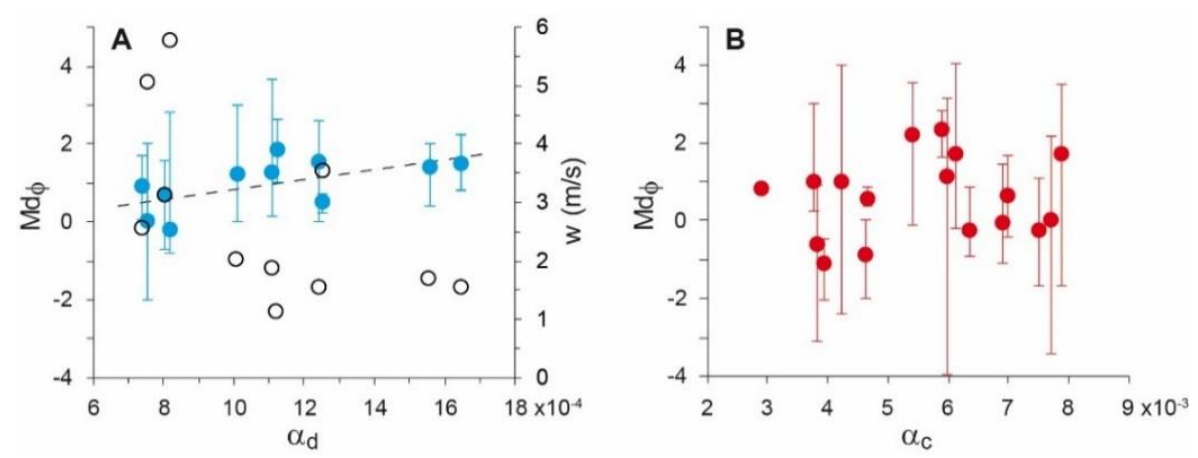

Fig. 6. Characteristics of particles of PDC deposits. (A) Dilute PDCs, with $\alpha_{d}=R_{d} / Q^{0.468}$ from Eq. 4. The mean grain size $\mathrm{Md}_{\phi}$ correlates positively with $\alpha_{\mathrm{d}}$, and open circles represent the mean particle settling velocity w. (B) Concentrated PDCs, with $\alpha_{c}=\mathrm{R}_{c} / \mathrm{Q}^{0.373}$ from Eq. 3. $\mathrm{Md}_{\phi}$ shows no correlation with $\alpha_{c}$. In (A) and (B) error bars represent the range of $\mathrm{Md}_{\phi}$ given in references. The data also illustrate a well-known effect of deposition from different PDCs, that deposits of dilute currents are in general finer grained and better sorted than those from concentrated flows.

\subsubsection{Concentrated currents}

In contrast to dilute PDCs there is no theory for estimating the settling velocity of particles in concentrated currents. This is because the fundamental physics controlling the deposit-flow interface in dense granular flows is still poorly known. Therefore, we estimate values of w by adapting a regression 
with missing data approach that we optimize by an ad-hoc numerical procedure, assuming that the power law relationships for both concentrated and dilute currents have the same, unknown exponent. As for dilute currents, the runout distance of concentrated PDCs should depend on the balance between advection and settling of solid particles (both depending on particle-particle and gas-particle interactions), and therefore should scale with $\mathrm{Q} / \mathrm{w}$, though the two types of currents have different physics. The values of the covariate $\mathrm{w}$ for concentrated PDCs, however, are unknown. Missing data is a major issue in many applied statistics fields and a myriad of methods to deal with them have been proposed. The most common approaches in generalized linear models with missing covariate data are maximum likelihood, multiple imputation, and Bayesian methods; none of them, however, is relevant for our study due to the small sample size and the relative high number of missing velocities $\mathrm{w}$. To overcome this issue, we revisit the regression optimization problem to estimate simultaneously the model parameters as well as the missing data of $w$ for concentrated PDCs. On this basis, we postulate that the regression coefficients for both dilute and concentrated PDCs are the same. In our case, only the values of $\mathrm{w}$ for dilute PDCs are known (with three exceptions) and they correspond to $n_{1}$ complete observations. For the sake of generality, we rewrite the regression model in two parts: the first concerns the completely log-scale observed data for dilute PDCs,

$$
R_{d}=\mu_{d}+X_{d} \beta+\alpha w_{d}+\varepsilon_{d}
$$

and the second one the partially log-scale observed data for concentrated PDCs,

$$
R_{c}=\mu_{c}+X_{c} \beta+\alpha w_{c}+\varepsilon_{c},
$$

where $\mathrm{R}=\left(\begin{array}{l}R_{d} \\ R_{c}\end{array}\right)$ describes the dependent variable observations (here $\mathrm{R}$ is completely observed), $\mathrm{X}=$ $\left[X_{d}, X_{c}\right]$ is a matrix of observations on $p$ explanatory variables, and $\beta$ is the vector of regression coefficients (including the intercepts that we denote $\mu_{d}$ and $\mu_{c}$ ). We denote $w_{c}$ a vector of missing data of the partially observed variable $\mathrm{W}=\left(\begin{array}{l}w_{d} \\ w_{c}\end{array}\right), \alpha$ is the unknown coefficient associated with it, and $\varepsilon=$ $\left(\begin{array}{l}\varepsilon_{d} \\ \varepsilon_{c}\end{array}\right)$ is an error vector. The estimation problem can be reduced to the simple constrained quadratic optimization problem:

$$
\left(\hat{\mu}, \hat{\alpha}, \hat{\beta}, \widehat{w_{c}}\right)=\underset{\mu, \alpha, \beta, w_{c}}{\operatorname{argmin}}\left\|\mathrm{R}-\mu-\mathrm{X}^{t} \beta-\alpha \mathrm{W}\right\|_{2}^{2} .
$$

Simple algebraic resolution of the problem yields the following parameter estimation:

where

$$
\hat{\alpha}=\frac{w_{d}^{\prime} M R_{d}}{w_{d}^{\prime} M w_{d}} \quad \text { and } \hat{\beta}=\left(X_{d}^{\prime} X_{d}\right)^{-1} X_{d}^{\prime}\left(R_{d}-\hat{\alpha} \mathrm{w}_{d}\right)
$$

$$
M=I_{n_{1}}-X_{d}\left(X_{d}^{\prime} X_{d}\right)^{-1} X_{d}^{\prime} .
$$

The $n_{1}$ available observations are then used to find imputed values for missing observations $w_{c}$. The method consists of running the regression of the complete observations and using the estimated $\hat{\alpha}$ and $\hat{\beta}$ to deduce the imputed values of the missing $w_{c}$ for concentrated PDCs:

$$
\widehat{w_{c}}=X_{c}\left(X_{d}^{\prime} X_{d}\right)^{-1} X_{d}^{\prime} w_{d}
$$

We find that the settling velocity of particles in concentrated PDCs are of same order of magnitude as in dilute turbulent currents (Fig. 7a, Supplementary Table 1). However, these velocities in concentrated flows do not depend on the mean particle size, thus highlighting physical processes that are fundamentally different from those in dilute currents.

Taking into account our estimates of $\mathrm{w}$, the power law obtained by fitting the data of concentrated PDCs,

$$
R_{c}=17 \times 10^{-4}(Q / w)^{0.456}
$$

has an exponent close to the theoretical value of 0.5 (Fig. 4b). The estimated exponent is close to the one obtained with only dilute PDC data (Eq. 6) because of uncertainties in the estimated missing values of $\mathrm{w}$. The particle settling velocity increases with runout, which suggests a possible influence of the topography on the settling rate (Fig. $7 \mathrm{~b}$ ). Considering a typical fall height $\mathrm{H}$, we find that the particle settling velocity decreases as the virtual angle defined as $\gamma=\arctan (\mathrm{H} / \mathrm{R})$ increases (Fig. 7c). This finding must be considered with caution because the fall height may vary considerably in nature. With this issue in mind, however, we argue that this tendency reflects hindered settling of particles when the flows propagate on steep slopes of volcanoes, possibly because the shear stress on particles at the depositional 
interface is higher than in case of subhorizontal slopes. Therefore, the effect of hindered settling increases as runout decreases, causing at given MDRs longer runouts than in case of subhorizontal substrate (note, however, that at low MDRs flow confinement in valleys of volcanic edifices can also cause longer runouts compared to unconfined topographies). Consequently, the power law relationship relating $\mathrm{R}$ to $\mathrm{Q}$ has an exponent significantly lower than 0.5 (Eq. 3). In contrast, the dynamics of dilute currents, including particle settling, are known to be independent of the slope angle (Britter and Linden, 1980), provided the effect of air entrainment is not too high (Esposti Ongaro et al., 2002). The negligible effect of the topography may explain why the power law relationships for runout of dilute currents as function of $\mathrm{Q}$ or $\mathrm{Q} / \mathrm{w}$ both have exponents $\sim 0.5$ (Eqs. 4 and 6). Note that the particle settling velocities we determine at $\gamma \sim 20^{\circ}$ for concentrated PDCs are higher, by close to an order of magnitude, than those measured in large-scale experiments by Breard et al. (2016). In summary, we provide estimates for particle settling velocities in concentrated PDCs based on a statistical analysis, but the effect of topography on the physical processes in currents at small MDRs and runouts requires further investigation.
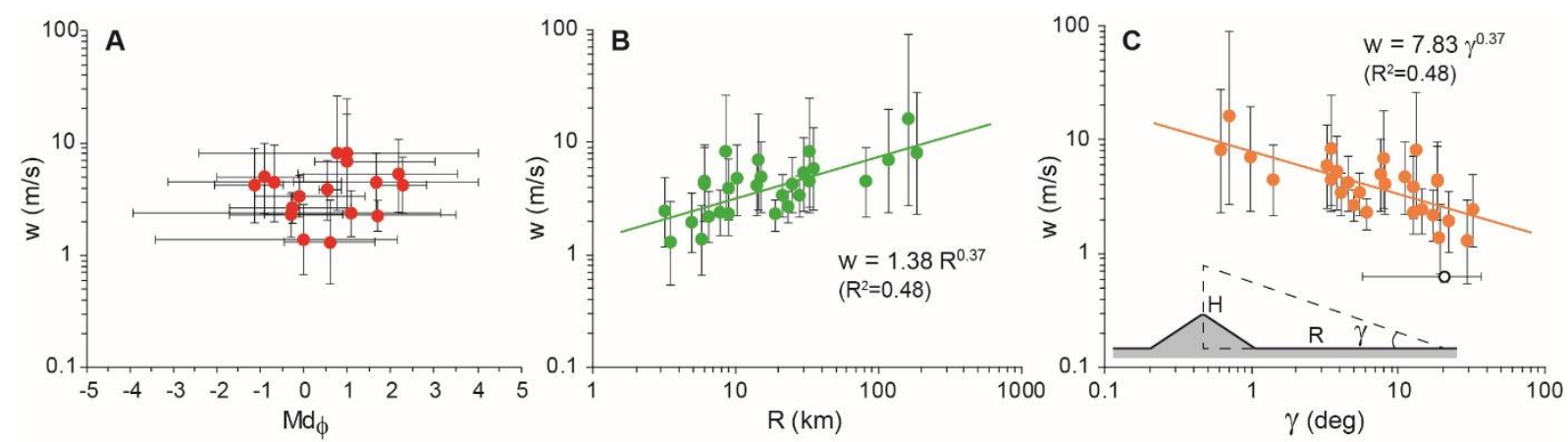

Fig. 7. Inferred particle settling velocity, w, in concentrated PDCs. The settling velocity is shown as function of (A) the mean grain size $\mathrm{Md}_{\phi}$, (B) the runout $\mathrm{R}$, or (C) a virtual slope angle $\gamma=\arctan (\mathrm{H} / \mathrm{R})$, with $\mathrm{H}=2 \mathrm{~km}$ a typical fall height equal to the height of the volcanic edifice plus that of the eruptive fountain (see inset). In (C) the black open circle indicates the data of Breard et al. (2016) for large scale experiments with PDC material.

\subsection{Relationships among other eruptive parameters}

Further analysis considering complementary data from another 53 PDCs whose MDRs are unknown (Supplementary Table 2) highlights other remarkable relationships among eruptive parameters. PDC runout increases with the volume of deposits (Fig. 8a). However, in contrast to the similar tendency of runout with MDR (Fig. 4), the data are increasingly scattered at increasing runouts and volumes, and they define less well-defined trends with $\mathrm{R}^{2}=0.80-0.82$ (compared to $\mathrm{R}^{2}=0.91-0.94$ in Fig. 4). Interestingly, the increase of runout with volume is consistent with the fact that volume correlates positively with MDR (Fig. 8b). This is in agreement with earlier findings (Carey and Sigurdsson, 1989) and reflects most probably more and larger diameter vents as volume increases. Note that the correlation of volume with MDR is significantly lower (i.e., $\mathrm{R}^{2}<0.75$ ) than that of runout with MDR $\left(\mathrm{R}^{2}>0.91\right)$, and the trends defined by the data for both dilute and concentrated PDCs nearly coincide. The mean deposit thickness $\sim 10^{-1}-10^{2} \mathrm{~m}$ increases with volume, and it is generally greater for concentrated PDC than for dilute ones, whereas thickness shows no correlation with MDR (Fig. 8c-d). We consider also the non-dimensional parameter defined by Breard et al. (2018),

$$
T_{d e-d i}=\frac{A^{3} d_{s, 1 / 2}}{V^{5 / 3} R^{2}}
$$

which aims to distinguish between dilute and concentrated PDC (Fig. 8e-f), with V and A the deposit volume and area, respectively, and $\mathrm{d}_{\mathrm{s}, 1 / 2}$ the Sauter (surface) particle mean diameter at $\mathrm{R} / 2$. Breard et al. (2018) propose that deposits of concentrated (versus dilute) PDC are characterized by $\mathrm{T}_{\text {de-di }}<\sim 2-5 \times 10^{-3}$ (conv. $>\sim 2-5 \times 10^{-3}$ ) when this parameter is plotted against volume. However, we do not find such a clear transition since the fields of both PDC types overlap; dilute $\mathrm{PDC}$ have $\mathrm{T}_{\text {de-di }}>\sim 3 \times 10^{-2}$ and concentrated ones have $\mathrm{T}_{\text {de-di }}$ up to $\sim 3 \times 10^{0}$ (except Ito). The same conclusion holds if $\mathrm{T}_{\mathrm{de}-\mathrm{di}}$ is plotted against MDR. 
This suggests that the parameter $\mathrm{T}_{\text {de-di, }}$, though perhaps applicable to small volume PDCs, should be considered with caution in the context of ignimbrites formed by accumulation of flow units during sustained eruptions because these units may have about the same runouts and areas while their accumulation increases the volume of the ignimbrites.
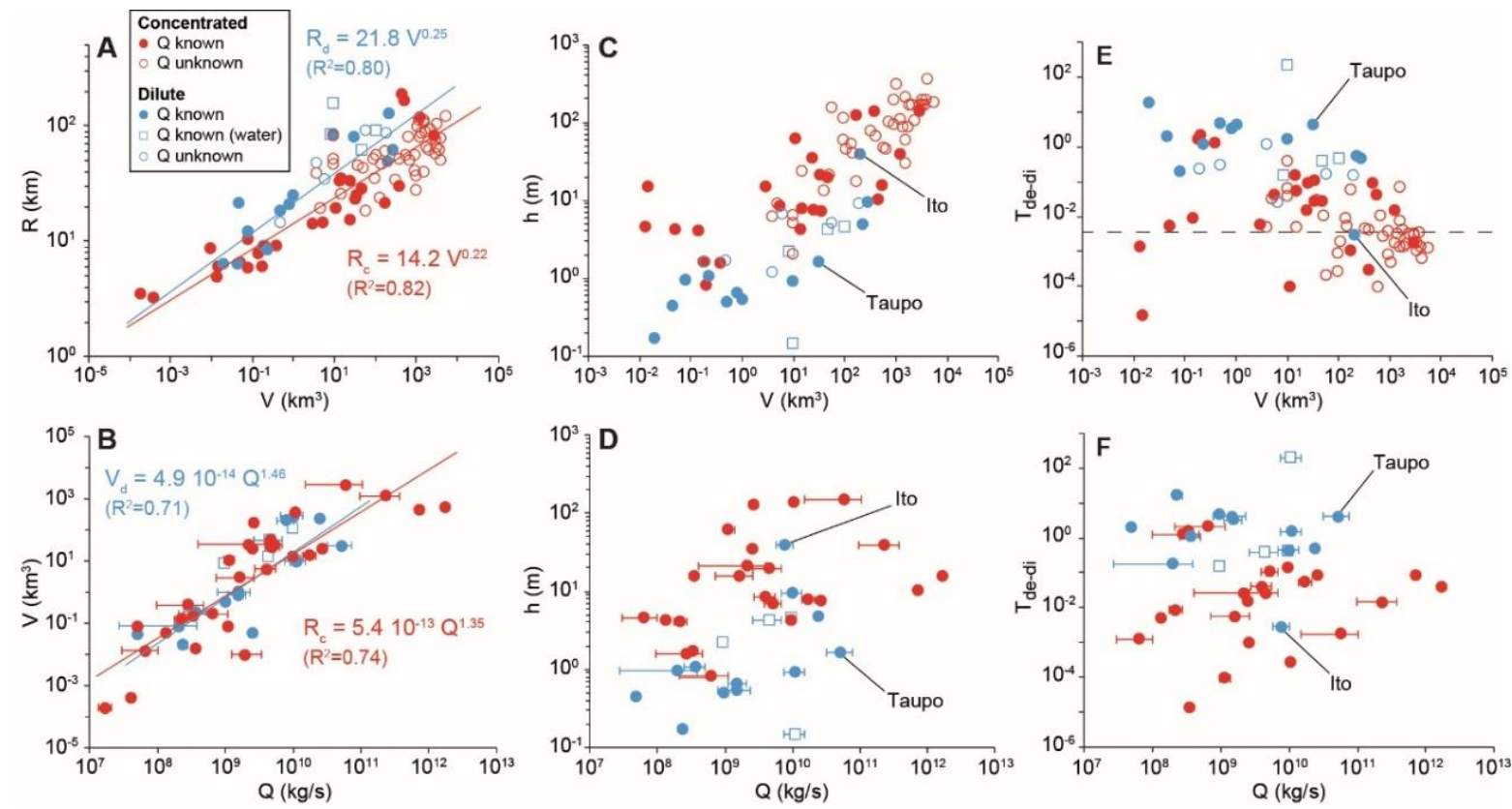

Fig. 8. Bivariate relationships between eruptive parameters. The parameters are PDC runout R, bulk volume of PDC deposits $\mathrm{V}$, mean mass discharge rate $\mathrm{Q}$, mean deposit thickness $\mathrm{h}$, and $\mathrm{T}_{\text {de-di }}$ as defined by Breard et al. (2018). Same legend for all graphs showing data of dilute or concentrated PDCs. (A-B) Best-fit lines are for data from PDCs on land. In (C-F) the data of Ito and Taupo discussed in the text are indicated. In (E) the dashed line indicates the transition between dilute (upper $\mathrm{T}_{\mathrm{de}-\mathrm{di}}$ values) and concentrated (lower $\mathrm{T}_{\mathrm{de-di}}$ values) PDCs given by Breard et al. (2018).

In order to distinguish between deposits of dilute versus concentrated PDCs we consider the classical deposit aspect ratio, AR, equal to the mean thickness over the diameter of a circular deposit of equivalent area (Walker, 1983). Fig. 9 shows that AR 10-5 $-10^{-2}$ does not correlate with volume, as already discussed by Walker (1983), and it further demonstrates that AR does not depend on MDR. However, our exhaustive dataset reveals a fairly sharp transition at AR $5 \times 10^{-5}$ between deposits of dilute and concentrated PDCs (except Ito, as discussed below).
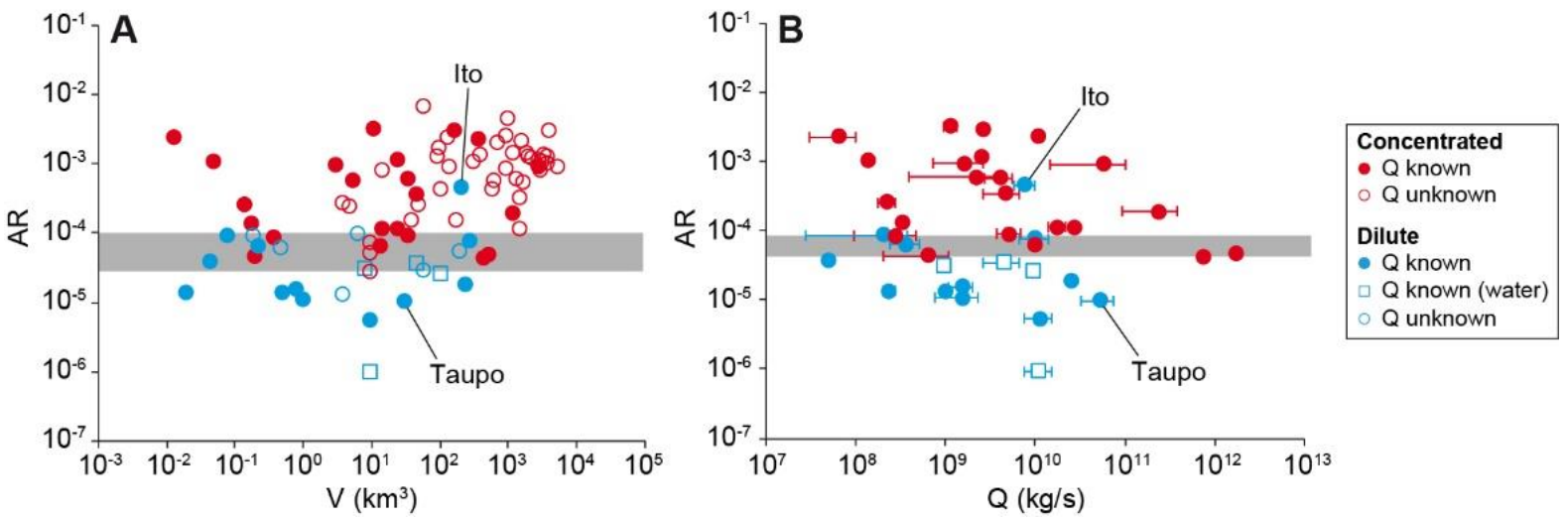

Fig. 9. Deposit aspect-ratio AR as functions of (A) the volume of PDC deposits, V, or (B) the mean mass discharge rate, Q. Gray areas indicate the transition between dilute and concentrated PDCs. The data of Ito and Taupo discussed in the text are indicated. 


\section{Discussion and implications}

\subsection{Inferring mass discharge rate from PDC runout}

The power law relationships given by Eqs. (3-4) show that, at given discharge rate, dilute PDCs on land have runouts generally longer than those of their concentrated counterparts (Fig. 4a). Taking into account the particle settling velocity, dilute PDCs over water travel about twice as far as they do on land (Fig. 4b). The cause of this greater mobility may be the internal flow of steam produced at the base of hot PDCs in contact with water (Dufek et al., 2007), which could delay settling of the particles. We acknowledge, however, that the data of dilute PDC over water are scarce and further investigation is required to confirm that these currents have in general longer runouts than those on land at a given MDR.

Equations (3-4) offer a simple and direct way to infer MDR from PDC runout (note that Eq. (6) may also be used for dilute currents provided the mean particle settling velocity is known). It is particularly valuable for investigating the dynamics of eruptions that did not produce plinian fall deposits, such as Cerro Galan (Cas et al., 2011), Coranzuli (Seggiaro et al., 2019), Huichapan (PachecoHoyos et al., 2018) and those of the Great Basin (Best et al., 2013; Henry and Faulds, 2010). It is also relevant in the context of numerically simulating PDCs, since MDR is a key input parameter for existing numerical models. From Eqs. (3-4), we give in Supplementary Table 2 estimates of MDR calculated from runouts of 53 PDCs, with a confidence probability of 80,90 and $95 \%$. As with the eruptions for which MDR estimates are available, we classified the PDCs according to the conclusions of authors in the publications. In particular, we find that super-eruptions such as Cerro Galan (Cas et al., 2011), Coranzuli (Seggiaro et al., 2019), Old Toba Tuff (Chesner and Rose, 1991), Oruanui (Wilson et al., 2001), Whakamaru (Froggatt et al., 1986) and those of Yellowstone (Christiansen, 2001; Knott et al., 2020 ) and the Great Basin (Best et al., 2013; Henry and Faulds, 2010) areas had MDRs $\sim 10^{10}-10^{11} \mathrm{~kg} / \mathrm{s}$. Oruanui $(25.4 \mathrm{ka})$, the second most recent super-eruption, had a MDR increasing up to $1.2 \times 10^{11} \mathrm{~kg} / \mathrm{s}$ and then decreasing to $1.4 \times 10^{10} \mathrm{~kg} / \mathrm{s}$ during the final phases $7-10$ according to variation in runout distances (Wilson et al., 2001).

\subsection{Transition of flow regime: the Ito (29 ka) and Taupo (AD 232) eruptions}

Though the well-defined power law relationships shown in Fig. 4 suggest that the distinction between dilute and concentrated PDCs is well-founded, it is conceivable that some currents experienced transition from the dilute to the concentrated flow regime owing to massive settling of particles during emplacement. We discuss two specific cases here, but it is likely that some other PDCs considered in our study may have experienced a transition of flow regime.

A first example is the $29 \mathrm{ka}$ Ito eruption. Baer et al. (1997) concluded that the Ito current was initially fully dilute and developed a gravity driven depositional system (i.e., two-layer current) at about half the runout distance, possibly because of a critical density stratification as suggested by Valentine (1987). Deposition of a massive concentrated basal part beyond half the runout distance is a likely explanation for the "abnormal" high aspect ratio of the Ito ignimbrite (Fig. 9). Note that if Ito is not considered in our analysis the runout of dilute PDCs scales with $(\mathrm{Q} / \mathrm{w})^{0.507}$, in almost perfect agreement with theory.

A second example is the AD 232 Taupo eruption, which generated an ignimbrite whose emplacement mechanisms are among the most debated issues in volcanology. The current that formed the most voluminous layer 2 ( $~ 82 \%$ of the total volume) as defined by Wilson (1985) could have undergone a regime transition like Ito, but under different flow conditions. The runout and aspect ratio of the Taupo ignimbrite both suggest emplacement from a dilute current (Figs. 4 and 9), in agreement with Dade and Huppert (1996). However, the ignimbrite has characteristics typical of deposits of concentrated flows (i.e., the so-called standard flow unit) at distances $>13-20 \mathrm{~km}$ from the vent where ponded in valleys (Wilson, 1985). These observations suggest that an initially fully dilute suspension, with a bedload that generated bedforms (including megaripples) in proximal areas, fed a concentrated basal flow (cf. Valentine, 1987; Breard et al., 2016) once it has propagated 13 to $20 \mathrm{~km}$. Relatively fast settling of the particles owing to their coarse mean size $\left(\mathrm{Md}_{\phi}=0\right.$, whole ignimbrite, Supplementary Table 
1) could have favored the emergence of the concentrated flow, which tended to drain into valleys to form the ponded ignimbrite ( $70 \%$ of the volume of layer 2 ), while deposition from the dilute suspension on topographic highs led to the associated ignimbrite veneer deposit with bedforms as recognized by Wilson (1985). As shown in Fig. 10, we propose that the concentrated basal flow arose from the bedload, which evolved to a dense mixture similar to that shown in Fig. 1b. The mixture was coupled to the driving dilute suspension, which had a high velocity caused by the highest MDR known for such currents, while at late stages it might have acquired some inertial movement as its particle concentration increased. The high velocity of the whole current $(\sim 100-300 \mathrm{~m} / \mathrm{s}$, Dade and Huppert, 1996; also suggested by the characteristics of layer 1) and the associated high basal shear stress could have delayed onset of deposition and/or caused slow aggradation of the concentrated basal part, thus causing a relatively thin deposit of mean thickness $\sim 1.6 \mathrm{~m}$. This particular two-layer model accounts for some key aspects of the layer 2 of the Taupo ignimbrite: a low aspect ratio, the aerodynamic equivalence of the largest pumice and lithic clasts, the decrease in mean grain size and sorting with distance for both the valley-ponded and the veneer deposits, and the decrease of the thickness of the veneer deposit with distance, all caused by the driving dilute upper part (cf. Dade and Huppert, 1996), while the standard flow unit resulted from deposition of the basal concentrated flow (cf. Wilson, 1985). Layer 1 might have been deposited essentially from the turbulent head of the current, but nonsystematic ordering with layer 2 suggests complex flow emplacement.

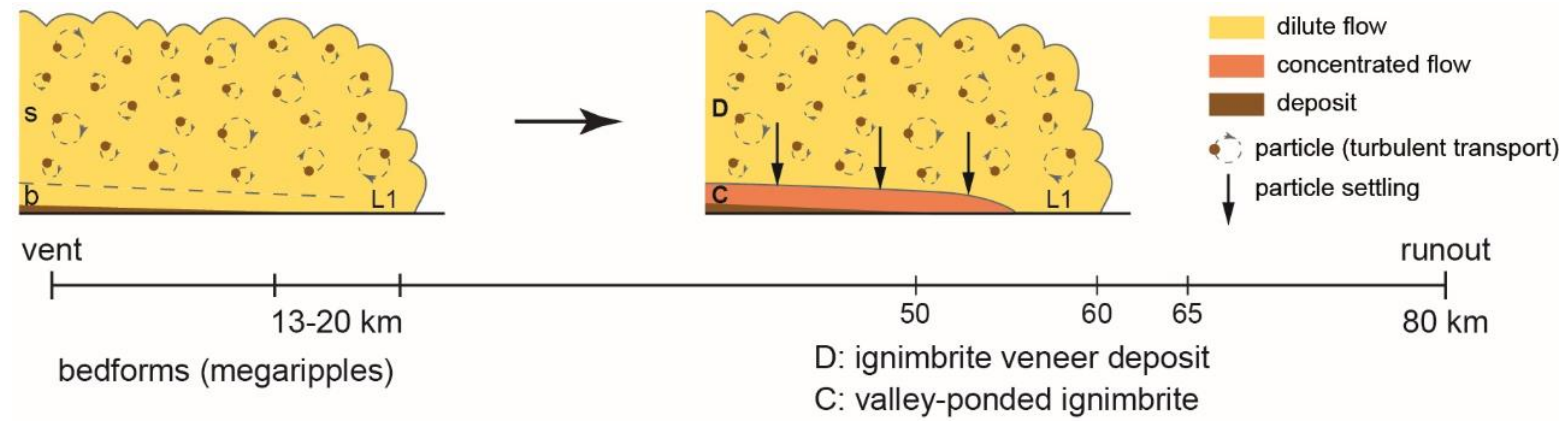

Fig. 10. Transition of flow regime during the AD 232 Taupo eruption, and deposits of layer 2 (terminology from Wilson, 1985). An initially dilute PDC with a suspended load (s) and a bedload (b) generates bedforms $<13-20 \mathrm{~km}$ from the vent before it transforms into a two-layer current with an upper dilute suspension (D) and a concentrated basal flow (C), which generate respectively the veneer deposit on topographic highs and the valley-ponded ignimbrite. Progressive flow transformation could explain the lack of systematic grading in valley-ponds in proximal areas. High particle settling rate from the dilute suspension causes the emergence of the concentrated flow (at the expense of the initial bedload), which remains coupled to the driving dilute suspension for most its emplacement while draining into valleys. Deposition of the concentrated flow occurs at low rate due to the high velocity of the whole current. Particle size segregation in the feeding dilute suspension causes decrease in mean grain size and sorting with distance, which is observed in both the veneer and valley-ponded deposits. A marked decrease in mean grain size and sorting in the valley-ponded ignimbrite is observed $>50-60 \mathrm{~km}$ from the vent, and the veneer deposit is discontinuous at distances $>60-65 \mathrm{~km}$ (Wilson, 1985). Layer 1 might have been deposited from the turbulent head of the current (L1), though not systematically.

\subsection{Analogy with lava flows}

It is well known since the seminal study of Walker (1973) that the runout of lava flows increases with the discharge rate of effusive eruptions. Further works showed that runout scales approximately with discharge rate to the power 0.5 (Harris and Rowland 2009), similarly to power laws we present for PDCs in this study. Considering fundamental flow processes, an analogy between lava flows and PDCs can be made. As stated above, the runout of PDCs depends on the balance between advection and settling of particles. In other words, PDCs propagate at a given velocity for a given timescale until the current is exhausted (or buoyancy reversal occurs). Cooling of lavas is analogous to particle settling in PDCs because it occurs for a typical timescale and therefore controls the runout of lava flows. Considering the effusive volume discharge rate, $\mathrm{Q}_{e}$, the initial lava temperature, $\mathrm{T}_{\mathrm{i}}$, and the cooling rate, $\tau$, a simple 
scaling analysis shows that $\left(\mathrm{Q}_{\mathrm{e}} \mathrm{T}_{\mathrm{i}} / \tau\right)^{2 / 3}$ for lava flows has the same dimension as Q'/w for PDC (i.e., $\left.\mathrm{m}^{2}\right)$. Therefore, runout of lava flows expanding radially is expected to scale as

$$
R_{l}=\left(\frac{Q_{e} T_{i}}{\tau}\right)^{1 / 3}
$$

Further work taking into account initial temperatures and cooling rates of lava flows will make it possible to verify whether the scaling predicted by Eq. (15) is correct.

\section{Conclusions} conclusions:

Our analysis of data from well-documented explosive eruptions leads to the following - The runout of concentrated (i.e. two-layer) and dilute PDCs increases with the mass discharge rate to the power 0.373 and 0.468 , respectively. At a given mass discharge rate, dilute PDCs have runouts generally longer than those of their concentrated counterparts. The power law relationships can be used reciprocally to infer mass discharge rate from a PDC's runout.

- While discharge rate controls PDC runout, increasing volumes of erupted material produce thicker PDC deposits.

- The strong correlations of the power law relationships suggest that the assumptions we make for calculating the mean runout distances and, above all, the mean discharge rates are sound. In this regard, we find that the discharge rate of the PDC-producing eruptive phase is on average 13.6 times greater than that of the preceding plinian phase.

- The runout of dilute PDCs increases with the ratio of the mass discharge rate over the particle settling velocity to the power $\sim 0.5$, in agreement with theory; scarce data suggest that dilute currents over water may travel about twice as far as they do on land. Assuming concentrated PDCs obey the same principle, we infer particle settling velocities of order $\sim 1-10 \mathrm{~m} \mathrm{~s}^{-1}$ for these currents.

- A threshold value $\sim 5 \times 10^{-5}$ for the deposit aspect ratio distinguishes dilute parent PDCs from concentrated ones. The deposit aspect ratio and other field evidence suggest possible transition from the dilute to the two-layer flow regimes during some eruptions such as Ito (29 ka) and Taupo (AD 232).

- The correlation we find between discharge rate and PDC runout is similar to that between effusive discharge rate and runout of lava flows. We propose that geophysical gravitational flows in general obey the same principle.

\section{CRediT authorship contribution statement}

OR conceived the study, built the database and took the lead in the writing of the manuscript. NA and AG did the statistical analysis. All the authors contributed to the interpretation of the results and to constructing the discussion.

\section{Declaration of competing interest}

The authors declare that they have no known competing financial interests or personal relationships that could have appeared to influence the work reported in this paper.

\section{Acknowledgments}

This work would not have been possible without the precious data acquired by field volcanologists during often long and sometimes hazardous missions. We thank A. Burgisser, R. Cioni, J.-L. Fernandez Turiel and G. Giordano for providing us with unpublished data. We are grateful to T. Esposti-Ongaro and an anonymous reviewer for meticulous and insightful comments. This project is part of the French government IDEX-ISITE initiative 16-IDEX-0001 (CAP 20-25). This is Laboratory of Excellence ClerVolc contribution $n^{\circ} 485$.

\section{Appendix A. Supplementary material}

Supplementary material related to this article can be found on-line at https://doi .org /10 .1016/j .epsl .2021.117017. 


\section{References}

Andrews, B., Manga, M., 2012. Experimental study of turbulence, sedimentation, and coignimbrite mass partitioning in dilute pyroclastic density currents. J. Volcanol. Geotherm. Res. 225-226, 30-44, doi: 10.1016/j.jvolgeores.2012.02.011.

Baer, E.M., Fisher, R.V., Fuller, M., Valentine, G., 1997. Turbulent transport and deposition of the Ito pyroclastic flow: determinations using anisotropy of magnetic susceptibility. J. Geophys. Res. 102, 22565-22586.

Best, M.G., Christiansen, E.H., Deino, A.L., Gromme, S., Hart, G.L., Tingey, D.G., 2013. The 36-18 Ma Indian Peak-Caliente ignimbrite field and calderas, southeastern Great Basin, USA: Multicyclic super-eruptions. Geosphere 9, 964-950, doi:10.1130/GES00902.1.

Bonnecaze, R.T., Huppert, H.E., Lister, J.R., 1996. Patterns of sedimentation from polydispersed turbidity currents. Proc. Roy. Soc. A 452, 2247-2261.

Branney, M.J., Kokelaar, B.P., 2002. Pyroclastic density currents and the sedimentation of ignimbrites. Geol. Soc., London, Memoirs 27.

Breard, E.C.P., Dufek, J., Lube, G. (2018). Enhanced mobility in concentrated pyroclastic density currents: An examination of a self-fluidization mechanism. Geophys. Res. Lett. 45, 654-664. https://doi.org/10.1002/2017GL075759.

Breard, E.C.P. Lube, G., Jones, J.R., Dufek, J., Cronin, S.J., Valentine, G.A., Moebis, A., (2016). Coupling of turbulent and non-turbulent flow regimes within pyroclastic density currents. Nat. Geosci. 9, 767-771, doi: 10.1038/NGEO2794.

Britter, R.E., Linden, P.F., 1980. The motion of the front of a gravity current travelling down an incline. J. Fluid Mech. 99, 531-543.

Brown, R.J., Branney, M.J., 2013. Internal flow variations and diachronous sedimentation within extensive, sustained, density-stratified pyroclastic density currents flowing down gentle slopes, as revealed by the internal architectures of ignimbrites on Tenerife. Bull. Volcanol. 75, 727, doi, 10.1007/s00445-013-0727-0.

Burgisser, A., 2005. Physical volcanology of the 2,050 BP caldera-forming eruption of Okmok volcano, Alaska. Bull. Volcanol. 67, 497-525.

Bursik, M.I., Woods, A.W., 1996. The dynamics and thermodynamics of large ash-flows. Bull. Volcanol. 58, 175193.

Carazzo, G., Kaminski, E., Tait, S., 2008. On the dynamics of volcanic columns: a comparison of field data with a new model of negatively buoyant jets. J. Volcanol. Geotherm. Res. 178, 94-103, doi: 10.1016/j.volgeores.2008.01.002.

Carey, S., Sigurdsson, H., 1989. The intensity of plinian eruptions. Bull. Volcanol. 51, 28-40.

Carey, S., Sigurdsson, H., Gardner, J.E., Criswell, C.W., 1990. Variations in column height and magma discharge during the May 18, 1980 eruption of Mount St. Helens. J. Volcanol. Geotherm. Res. 43, 99-112.

Cas, R.A.F., Wright, H.M.N., Folkes, C.B., Lesti, C., Porreca, M., Giordani, G., Viramonte, J.G., 2011. The flow dynamics of an extremely large volume pyroclastic flow, the 2.08-Ma Cerro Galán Ignimbrite, NW Argentina, and comparison with other flow types. Bull. Volcanol. 73, 1583-1609, doi: 10.1007/S00445-011-0564-Y.

Cas, R.A.F., Wright, J.V., 1987. Volcanic successions, modern and ancient, first ed. Chapman and Hall, London.

Chesner, C.A., Rose, W.I., 1991. Stratigraphy of the Toba tuffs and the evolution of the Toba caldera complex, Sumatra, Indonesia. Bull. Volcanol. 53, 343-356.

Christiansen, R.L., 2001. The Quaternary and Pliocene Yellowstone plateau volcanic field of Wyoming, Idaho, and Montana. U.S. Geol. Surv. Prof. Pap. 729-G, 156 pp.

Cook, G.W., Wolff, J.A., Self, S., 2016. Estimating the eruptive volume of a large pyroclastic body: the Otowi Member of the Bandelier Tuff, Valles caldera, New Mexico. Bull. Volcanol. 78, 10, doi: 10.1007/s00445-0161000-0.

Costa, A., Gottsmann, J., Melnik, O., Sparks, R. S. J., 2011. A stress-controlled mechanism for the intensity of very large magnitude explosive eruptions. Earth Planet. Sci. Lett. 310, 161-166, doi: 10.1016/j.epsl.2011.07.024.

Costa, A., Smith, V.C., Macedonio, G., Matthews, N.E., 2014. The magnitude and impact of the Youngest Toba Tuff super-eruption. Front. Earth Sci., 2: 16, doi: 10.3389/feart.2014.00016.

Costa, A., Suzuki, Y.J., Koyaguchi, T., 2018. Understanding the plume dynamics of explosive super-eruptions. Nat. Commun. 9, 654, doi: 10.1038/s41467-018-02901-0.

Crosweller, H.S., Arora, B., Brown, S.K., Cottrell, E., Deligne, N.I., Guerrero, N.O., Hobbs, L., Kiyosugi, K., Loughlin, S.C., Lowndes, J., Nayembil, M., Siebert, L., Sparks, R.S.J., Takarada, S., Venzke, E., 2012. Global database on large magnitude explosive volcanic eruptions (LaMEVE). J. Applied Volcanol. 1, 4. http://www.appliedvolc.com/content/1/1/4.

Dade, W.B., Huppert, H.H., 1995. Runout and fine-sediment deposits of axisymmetric turbidity currents. J. Geophys. Res. 100, 18597-18609. 
Dade, W.B., Huppert, H. E., 1996. Emplacement of the Taupo ignimbrite by a dilute turbulent flow. Nature 381, 509-512.

Dellino, P., Dioguardi, F., Doronzo, D.M., Mele, D., 2019. The rate of sedimentation from turbulent suspension: An experimental model with application to pyroclastic density currents and discussion on the grain-size dependence of flow runout. Sedimentology 66, 129-145, doi: 10.1111/sed.12485.

Dufek, J., Bergantz, G.W., 2007. Dynamics and deposits generated by the Kos Plateau Tuff eruption: Controls of basal particle loss on pyroclastic flow transport. Geoch. Geophys. Geosyst. 8, Q12007, doi: 10.1029/2007GC001741.

Dufek, J., Manga, M., Staeder, M., 2007. Littoral blasts: Pumice-water heat transfer and the conditions for steam explosions when pyroclastic flows enter the ocean. J. Geophys. Res. 112, B11201, doi: 10.1029/2006JB004910.

Esposti Ongaro, T., Neri, A., Menconi, G., de'Michieli Vitturi, M., Marianelli, P., Cavazzoni, C., Erbacci, G., Baxter, P.J., 2008. Transient 3D numerical simulations of column collapse and pyroclastic density current scenarios at Vesuvius. J. Volcano. Geotherm. Res. 178, 378-396, doi:10.1016/j.jvolgeores.2008.06.036.

Esposti Ongaro T., Neri, A., Todesco, M., Macedonio, G., 2002. Pyroclastic flow hazard assessment at Vesuvius (Italy) by using numerical modeling. II. Analysis of flow variables. Bull. Volcanol. 64(3-4), 178-191. http://doi.org/10.1007/s00445-001-0190-1.

Esposti Ongaro, T., Widiwijayanti, C., Clarke, A.B., Voight, B., Neri, A., 2011. Multiphase-flow numerical modeling of the 18 May 1980 lateral blast at Mount St. Helens, USA. Geology 39, 535-538, doi: 10.1130/G31865.1.

Fauria, K.E., Manga, M., Chamberlain, M., 2016. Effect of particle entrainment on the runout of pyroclastic density currents. J. Geophys. Res.: Solid Earth 121, 6445-6461, doi: 10.1002/2016JB013263.

Froggatt, P.C., Nelson, C.S., Carter, L., Griggs, G., Black, K.P., 1986. An exceptionally large late Quaternary eruption from New Zealand. Nature 319, 578-582.

Harris, A.J.L., Rowland, S.K., 2009. Effusion rate control on lava flow length and the role of heat loss: a review. In: T. Thordarson, T., Self, S., Larsen, G., Rowland, S.K., Hoskuldsson, A. (Eds.), Studies in volcanology: The legacy of George Walker. Geol. Soc. London, 2: 33-51.

Hastie, T., Tibshirani, R., Friedman, J., 2009. The elements of statistical learning. Data mining, inference, and prediction. Second edition (Springer Series in Statistics. Springer, New York.

Henry, C.D., Faulds, J.E., 2010. Ash-flow tuffs in the Nine Hill, Nevada, paleovalley and implications for tectonism and volcanism of the western Great Basin, USA. Geosphere 6, 339-369, doi: 10.1130/GES00548.1.

Knott, T.R., Branney, M.J., Reichow, M.K., Finn, D.R., Tapster, S., Coe, R.S., 2020. Discovery of two new supereruptions from the Yellowstone hotspot track (USA): Is the Yellowstone hotspot waning? Geology 48, 934938. https://doi.org/10.1130/G47384.1.

Koyaguchi, T., Suzuki, Y.J., Kozono, T., 2010. Effects of the crater on eruption column dynamics. J. Geophys. Res. 115, B07205, doi: 10.1029/2009JB007146.

Lube, G., Breard, E.C.P., Jones, J., Fullard, L., Dufek, J., Cronin, S.J., Wang, T., 2019. Generation of air lubrication within pyroclastic density currents. Nat. Geosci. 12, 381-386. https://doi.org/10.1038/s41561-019-0338-2.

Mason, B.G., Pyle, D.M., Oppenheimer, C., 2004. The size and frequency of the largest explosive eruptions on Earth. Bull. Volcanol. 66, 735-748, doi: 10.1007/s00445-004-0355-9.

Mastin, L.G., Guffanti, M., Servranckx, R., Webley, P., Barsotti, S., Dean, K., Durant, A., Ewert, J.W., Neri, A., Rose, W.I., Schneider, D., Siebert, L., Stunder, B., Swanson, G., Tupper, A., Volentik, A., Waythomas, C.F., 2009. A multidisciplinary effort to assign realistic source parameters to models of volcanic ash-cloud transport and dispersion during eruptions. J. Volcanol. Geotherm. Res. 186, 10-21, doi:10.1016/j.jvolgeores.2009.01.008.

Newhall, C., Self, S., Robock, A., 2018. Anticipating future Volcanic Explosivity Index (VEI) 7 eruptions and their chilling impacts. Geosphere 14, 572-603, doi:10.1130/GES01513.1.

Pacheco-Hoyos, J.G., Aguirre-Díaz, G.J., Dávila-Harris, P., 2019. Boiling-over dense pyroclastic density currents during the formation of the $\sim 100 \mathrm{~km}^{3}$ Huichapan ignimbrite in Central Mexico: Stratigraphic and lithofacies analysis. J. Volcanol. Geotherm. Res. 349, 268-282. https://doi.org/10.1016/j.jvolgeores.2017.11.007.

Roche, O., Buesch, D.C., Valentine, G.A., 2016. Slow-moving and far-travelled dense pyroclastic flows during the Peach Spring super-eruption. Nat. Commun. 7, 10890, doi: 10.1038/ncomms10890.

Self, S., 2006. The effects and consequences of very large explosive volcanic eruptions. Phil. Trans. R. Soc. A 364, 2073-2097, doi:10.1098/rsta.2006.1814.

Seggiaro, R.E., Guzmán, S.R., Martí, J., 2019. Dynamics of caldera collapse during the Coranzulí eruption (6.6 Ma) (Central Andes, Argentina). J. Volcanol. Geotherm. Res. 374, 1-12. https://doi.org/10.1016/j.jvolgeores.2019.02.003.

Shimizu, H.A., Koyaguchi, T., Suzuki, Y.J., 2019. The run-out distance of large-scale pyroclastic density currents: A two-layer depth-averaged model. J. Volcanol. Geotherm. Res. 381, 168-184. https://doi.org/10.1016/j.jvolgeores.2019.03.013. 
Valentine, G.A., 1987. Stratified flow in pyroclastic surges. Bull. Volcanol. 49, 616-630.

Valentine, G.A., 2020. Initiation of dilute and concentrated pyroclastic currents from collapsing mixtures and origin of their proximal deposits. Bull. Volcanol. 82, 20. https://doi.org/10.1007/s00445-020-1366-x.

Walker, G.P.L., 1973. Lengths of lava flows. Phil. Trans. R. Soc. London A 274, 107-118.

Walker, G.P.L., 1983. Ignimbrite types and ignimbrite problems. J. Volcanol. Geotherm. Res. 17, 65-88.

Wilson, C.J.N., 1985. The Taupo eruption, New Zealand II. The Taupo ignimbrite. Phil. Trans. Roy. Soc. London A $314,229-310$.

Wilson, C.J.N., 2001. The 26.5 ka Oruanui eruption, New Zealand: an introduction and overview. J. Volcanol. Geotherm. Res. 112, 133-174.

Wilson, L., Sparks, R., Walker, G., 1980. Explosive volcanic eruptions-IV. The control of magma properties and conduit geometry on eruption column behaviour. Geophys. J. Int., 63(1), 117-148. 